\title{
Legal issues of veterinary services for shelters for stray animals in the Russian Federation
}

\author{
Mihail N. Vasiliev*, Ivan N. Nikitin, Anastasia A. Butova and Anastasia I. Vasilieva \\ Kazan State Academy of Veterinary Medicine named after N. E. Bauman, Kazan, 420029, Russia
}

\begin{abstract}
The important problem of urban and large rural settlements of the Russian Federation is the increase in the number of stray animals. The activities of shelters for stray animals are associated with a number of obligatory veterinary preventive measures. These measures require the development of a comprehensive system of veterinary services for animal shelters, including the procedure for the initial reception of an animal to a shelter, the procedure to identify an animal without owners showing unmotivated aggressiveness, a system of veterinary preventive measures in a shelter, a method of humane treatment of animals in a shelter, a typical staffing of veterinary shelter specialists and a typical diet for an animal in a shelter. In many constituent entities of the Russian Federation, the activities to regulate the number of stray animals are carried out by private specialized organizations in accordance with the concluded municipal contracts. The existing practice does not allow organizing a single effective system to regulate the number of stray animals. A regional system for the regulation of the number of stray animals could be organized under the leadership of the State Veterinary Service of the constituent entities of the Russian Federation in cooperation with existing private shelters for stray animals. This system can not be created without an appropriate regional regulatory framework. The authors propose the development and implementation of a comprehensive system of veterinary services for animal shelters at the level of a constituent entity of the Russian Federation. This system will serve as one of the elements to maintain the epizootic and epidemic well-being of the territories of the constituent entities of the Russian Federation for zooanthroponosis, among which rabies is the most relevant.
\end{abstract}

\section{Introduction}

One of the serious problems of urban and large rural settlements of the Russian Federation is stray animals and, in particular, an uncontrolled increase in their number. This situation endangers the life and health of pets, as well as humans. An infectious disease such as rabies transmitted through the bite of a sick animal is fatal for humans [1]. The researchers in other countries of the world, such as the USA [2], Germany [3, 4], Poland $[5,6]$ and others also touch upon this issue in their works.

In Russia, legislatively regulated work with stray animals began in 2019 with the adoption of the Federal Law of December 27, 2018 No. 498 - FL "On the Responsible Treatment of Animals and on Amendments to Certain Legislative Acts of the Russian Federation". There are different opinions on the feasibility of the strategy proposed by the law for working with stray animals [7], but the norm of the already adopted federal law must be implemented at the regional level.

The legal and regulatory framework of the constituent entities of the Russian Federation in terms of the organization of the activities of shelters does not fully regulate the implementation of antiepizootic measures in shelters and, in general, the organization of veterinary services for shelters for stray animals. It is necessary to legislatively regulate the issues of humane treatment, feeding, veterinary services for stray animals kept in shelters. This is one of the elements to maintain the epidemic and epizootic well-being of the territories of the constituent entities of the Russian Federation for zooanthroponotic diseases, among which rabies is the most urgent one.

\section{Materials and methods}

The material for the research was the legal framework regulating the activities of shelters for stray animals in the constituent entities of the Volga Federal District of the Russian Federation.

The studies were carried out at the Department of Organization of Veterinary Affairs of the Kazan State Academy of Veterinary Medicine named after N.E. Bauman. During the research the authors used abstract logical and monographic research methods.

\section{Research results}

In the Russian Federation, the current regulatory framework regulating the organization of veterinary

\footnotetext{
*Corresponding author: mnvasiliev@ mail.ru
} 
services for animals, including the prevention and elimination of infectious diseases is being actively developed and improved [8]. However, as a result of the lack of a federal regulatory framework, due attention has not been paid to the issues of veterinary services for shelters for stray animals. In connection with the adoption of the Federal Law "On the Responsible Treatment of Animals and on Amendments to Certain Legislative Acts of the Russian Federation", it became necessary to develop a number of regional regulatory documents regulating the activities of animal shelters and, in particular, the organization of their veterinary services.

The authors found that in all 14 constituent entities of the Volga Federal District of the Russian Federation there was a legal framework regulating the work and veterinary services of shelters for stray animals. The Procedure for the organization of the activities of animal shelters and norms for keeping animals in them, as well as the Procedure for the implementation of activities for the treatment of stray animals, were developed everywhere.

The first document in all constituent entities of the Volga Federal District is uniform and has the following main sections: the requirements for the placement and construction of shelters, the procedure for animals entering a shelter, keeping animals in a shelter, feeding and drinking animals and the requirements for walking and waste disposal. Despite this, in some regions the document is set out in more detail, for example, in the Chuvash, Mordovia, Udmurt Republics, Tatarstan, Mari El, Penza, Kirov, Nizhny Novgorod and Orenburg regions, Perm Territory.

The longest and most detailed document is the Procedure developed in the Republic of Tatarstan. It additionally details the requirements for the placement of a shelter, the procedure for the reception of animals to a shelter, the requirements for premises, including keeping animals, crates and cages, the procedure for their disinfection, requirements for walking, feeding and watering animals, returning animals to their former habitats, quarantine procedures and requirements for a quarantine room, the procedure for preventive, antiepizootic measures, requirements for a veterinary center, a hospital for animals and their equipment. The document contains a list of appendices, including an act of inspection and transfer of a trapped stray animal to a shelter, a book for recording the arrival and departure of animals from a shelter, the norms for the area of isolated compartments, cages, cabins and walking areas.

In regional regulations, little attention is paid to the requirements for premises for long-term animal housing. It is important to indicate the temperature regime in the premises, humidity, illumination, materials from which the walls and floors of the crates should be made, the area of individual and common enclosures for keeping animals, as well as walking areas. The mode of feeding, balance of the diet and the physiological state of the animals is important.

The work of the veterinary unit, as well as the veterinary specialists directly at a shelter, is also very important. It is necessary to clearly regulate the area and its division into special sections (surgery, therapy, hospital and preventive treatment room), the necessary equipment, drugs, instruments for surgical and therapeutic manipulations, dressings and other expendables.

The procedure for the implementation of activities to treat stray animals has been developed in all subjects and consists of the following sections: organization of events during the implementation of activities to treat stray animals, trapping stray animals, transportation and transfer to a shelter, keeping stray animals, registration of stray animals, placement of animals, sterilization, euthanasia and disposal of corpses, return of animals to their owners. This procedure is presented in more detail in the Nizhny Novgorod, Kirov, Orenburg, Samara regions, the Chuvash Republic, the Republic of Tatarstan and Udmurtia.

The developers of the documents describe the processes of catching, transporting, temporary keeping and accounting of animals, as well as transferring animals back to their owners. The most detailed Procedure has been worked out in the Penza region. It regulates in more detail the issues of receiving messages about finding an animal without owners, trapping, transporting and immediately transferring them to shelters, keeping animals and their euthanasia. The procedure for the implementation of activities to treat stray animals has been developed not so thoroughly in Bashkiria, Mordovia, Mari El, Saratov and Ulyanovsk regions.

It is necessary to note that a common disadvantage is the section on animal euthanasia, since no document defines a specific list of pathologies and injuries in which this manipulation is allowed. The term "euthanasia in a humane way" is widely used. However the meaning of it is not explained, neither the procedure itself nor the list of permitted veterinary drugs is regulated.

In addition to two presented documents in the Nizhny Novgorod region, the Republics of Mari El, Bashkortostan and Tatarstan, there are other normative legal acts regulating this area. In the Nizhny Novgorod region they are the Law on stray animals in the Nizhny Novgorod region and the Law on keeping pets in the Nizhny Novgorod region. In the Republic of Mari El the Procedure for the organization and implementation of state supervision in the field of treatment of animals on the territory of the Republic of Mari El is developed. In the Republic of Bashkortostan there is the Law on Responsible Treatment of Animals. In the Republic of Tatarstan there is the Law on the regulation of certain issues in the field of animal management.

One of the fundamental documents regulating the studied sphere of activity in the constituent entity of the Russian Federation is the procedure for the organization of the activities of animal shelters and the norms for keeping animals in them on the territory of the region. The "Procedure for the organization of the activities of animal shelters and norms for keeping animals in them on the territory of the Republic of Tatarstan" was developed with our participation. It was approved by the Resolution of the Cabinet of Ministers of the Republic of 
Tatarstan on February 28, 2020 No. 150. During the preparation of the document, we developed our own project, including the requirements for keeping animals in shelters, requirements for the placement of a shelter and the arrangement of shelter premises, requirements for the operation of a shelter and a number of annexes (Act of primary veterinary examination of an animal entering a shelter, Agreement on transferring an animal into ownership (under guardianship), Animal registration card, registration card of animals in a shelter, Act of death of a stray animal, Application and Questionnaire to obtain a permanent pass to a shelter).

In our opinion, it is necessary to adhere to the following steps and activities when keeping animals in a shelter:

- the initial examination and assessment by a veterinary specialist of the physical condition of animals entering a shelter;

- the provision of emergency veterinary care and treatment of animals (if necessary);

- the registration of all animals entering a shelter on paper or electronic media;

- the return of lost animals to their owners in case of availability of information about owners;

- the compulsory quarantine for 10 days of animals entering shelters;

- the marking (tagging) of animals with nonremovable and indelible marks;

- the vaccination against rabies and veterinary treatments against other diseases dangerous to humans and animals:

- the sterilization (castration) in order to reduce the number of animals without owners preventing the appearance of unwanted offspring, improving the epizootic and epidemic situation;

- the daily keeping of animals;

- the search for new owners for animals without owners entering shelters and animals the ownership rights of which were abandoned by the owners, transferred to new owners under an agreement;

- the return to their former habitats of vaccinated, marked and sterilized stray animals, not expressing unmotivated aggressiveness;

- keeping stray animals in a shelter, which can not be returned to their former habitats, until such animals are transferred to new owners or natural death occurs;

- euthanasia of animals if it is necessary to end the intolerable physical suffering of non-viable animals, in the presence of a serious incurable disease of an animal or incurable consequences of an acute trauma fatal to an animal, reliably established by a specialist in the field of veterinary medicine.

Keeping an animal in a shelter ends in the following cases:

- the return of a vaccinated and sterilized stray animal, not expressing unmotivated aggressiveness, to its former habitat;

- the return of lost animals to their owners;

- the transfer of the vaccinated, sterilized and nonaggressive animal kept in a shelter to a new owner;

- the transfer of an animal to another shelter;
- euthanasia of an animal if it is necessary to stop the unbearable physical suffering of an unviable animal, in the presence of a serious incurable disease of an animal or incurable consequences of an acute trauma fatal to an animal, reliably established by a specialist in the field of veterinary medicine;

- the natural death of an animal.

The requirements for the placement of a shelter and the arrangement of a shelter premises include the requirements for the property complex of a shelter. They regulate the sanitary protection zone of a shelter, the presence of an equipped year-round functioning disinfection barrier and a closed fence. The requirements for water supply, sewerage, electricity and heat supply, outdoor lighting, ventilation and the premises for keeping animals. Shelters are located in specially designed buildings, structures and must have:

- crates for keeping dogs;

- area for walking dogs;

- heated ventilated rooms for keeping puppy dogs, dogs with a coat that does not allow them to be kept in open crates of a shelter (during the year, the temperature in them must be maintained within the range from $+16^{\circ}$ c to $+26^{\circ} \mathrm{c}$ );

- heated ventilated rooms for keeping cats (during the year, the temperature in them must be maintained within the range from $+16^{\circ} \mathrm{c}$ to $+26^{\circ} \mathrm{c}$ );

- a hospital room;

- a quarantine room;

- veterinary unit;

- sanitary block;

- disinfection and washing room;

- a utility room for service personnel;

- utility rooms to store feed, providing storage conditions specified by the producer of feed, or a feed kitchen to prepare feed from natural products;

- a warehouse to store bedding material and cleaning equipment;

- a freezer for temporary storage of biological waste;

- a container platform.

The requirements for the activities of a shelter should determine that the following animals should be kept separately in a shelter: sick, weakened as a result of poor nutrition or physiological condition, young animals during milk feeding, females with calves, aggressive animals, females during sexual activity, females with obvious signs of late pregnancy or prenatal period. Newborn animals must be kept with the mother until the end of the natural feeding period (at least 1 month from the date of birth). It is forbidden to combine animals of different species and aggressive animals in a group keeping, to form stable groups (flocks) from different habitats.

We have regulated a list of activities related to the daily maintenance of animals, including the procedure for the initial examination and assessment by a veterinary specialist of the physical condition of animals entering a shelter; daily examination by a specialist in the field of veterinary medicine of all animals and their places of keeping; the procedure for vaccination against rabies and veterinary treatments against other diseases dangerous to humans and animals; the procedure for 
feeding animals, recommendations to establish the number of staff at a shelter.

The staff of a shelter, in addition to the administrative and managerial personnel, is recommended to provide service personnel, specialists in the field of veterinary medicine, specialists in the social adaptation of animals (dog handlers, felinologists) and technical personnel. The recommended workload per 1 maintenance staff of cleaning, disinfecting premises and feeding animals is 30 animals. Veterinary services at a shelter are carried out by their own hired specialists in the field of veterinary medicine or by a third-party veterinary organization under a veterinary service agreement. The procedure for disinfection, deratization and disinfestation of the premises and territory of a shelter, collection, removal of biological waste and their destruction or disposal was determined. The owners of animal shelters and their authorized persons are obliged to ensure the possibility of visiting a shelter:

- by citizens at the time specified by a shelter, except for the days on which the premises are disinfected;

- volunteers, public inspectors in the field of animals during the hours established by the working hours of a shelter, with the exception of days when the premises are disinfected.

The general rules for visiting a shelter by citizens, volunteers, public inspectors in the field of animals, other persons, as well as humanitarian aid were determined.

In our opinion, the draft document prepared by us provides a more detailed regulation of certain issues of the activity of shelters, in particular, the issues of keeping an animal in a shelter and initial examination. The procedure for transferring an animal to new owners from a shelter or to a temporary facility for keeping is described in more detail.

More attention is paid to humane and animal-safe keeping in a shelter, as well as the forms of acts and journals necessary to maintain the document flow of an organization are attached: the Act of the primary veterinary examination of an animal entering a shelter, the Agreement on the transfer of an animal into ownership (guardianship), Animal registration card, Journal of movement of animals in a shelter, Act of death of a stray animal, Application form to issue a pass to the territory of a shelter, Application form to obtain a permanent pass.

One of the important issues in the legal regulation of the activities of shelters for stray animals is to determine the procedure to find stray animals expressing unmotivated aggressiveness. Today no recommendations have been developed to determine such an order by the executive authorities of the constituent entities of the Russian Federation At the federal level.

In the fall of 2020, the draft "Guidelines for the development by the constituent entities of the Russian Federation of the procedure for the organization and implementation by the executive authorities of the constituent entities of the Russian Federation to find stray animals expressing unmotivated aggressiveness" was not approved at the federal level. We have proposed our own draft document, set out in the following form:

The provisions of Article 18 of the Federal Law of December 27, 2018 No. 498-FL "On the Responsible Treatment of Animals and Amendment of Certain Legislative Acts of the Russian Federation" (hereinafter - Law No. 498-FL), stray animals expressing unmotivated aggressiveness can not be returned to their former habitats and previously released animals are subject to trapping with further placement in an animal shelter (hereinafter referred to as a shelter).

In our opinion, the following paragraph should be included:

In accordance with the requirements of Law No. 498FL, this category of animals is placed in shelters until the natural death of such animals or the transfer of such animals to new owners. It is prohibited to kill animals kept in animal shelters, except in cases where it is necessary to end the intolerable physical suffering of non-viable animals, in the case of a serious incurable disease of an animal or incurable consequence of an acute trauma fatal to animal, reliably established by a specialist in the field of veterinary medicine.

In view of the different budgetary provision of the constituent entities of the Russian Federation and the objective shortage of places for the placement of animals in shelters, it is necessary to distinguish between animals expressing unmotivated aggressiveness (subject to obligatory and immediate isolation) from animals expressing other forms of behavior undesirable for humans (primarily, expressing increased aggressiveness), for which trapping with subsequent placement in a shelter is also desirable, but only if there is a sufficient number of free places and the possibility of further maintenance.

We propose to supplement the paragraph with the following content: Such animals, expressing increased aggressiveness, and in some cases unmotivated aggressiveness, also include those without owners in the territory of settlements, potentially dangerous dog breeds and their hybrids that can harm health and life a person defined by the Decree of the Government of the Russian Federation of July 29, 2019 No. 974 "On Approval of the List of Potentially Dangerous Dogs" (hereinafter referred to as Potentially Dangerous Dogs).

Unmotivated aggressiveness is a behavioral defect (disorder) of various etiologies. It is expressed in atypical behavior of animals of particular species, and manifested in the form of aggression (including autoaggression).

For the purposes of this method, aggression is understood as the actions of an animal aimed at to inflict physical injuries on a person or another animal.

The particular danger of this behavior is connected with:

- unpredictability;

- impossibility of correction in natural conditions;

- suspected disease of an animal with rabies.

Due to the fact that in many cases "stray animals" living in the territory of settlements are associated with humans (socialized) dogs and cats to different degrees, it is advisable to focus on these categories of animals. 
The main feature of the work to find animals expressing unmotivated aggressiveness is that this work is carried out with populations of free-living animals in order to eliminate the threat to humans and other animals from individuals of this population and in this very place. Animals exist in a natural environment and have a natural way of life for their species, which has daily and seasonal characteristics. In this case, cats and, in particular, dogs interact in groups and the behavior of an individual must be assessed exclusively in the context of group behavior.

All the messages from individuals and legal entities concerning the treatment of stray animals are subject to transfer, processing and consideration by a person who is responsible for the activities for the treatment of stray animals in accordance with the requirements of Law No. 498-FL and the regulatory legal acts of the constituent entity of the Russian Federation.

Next, we propose to include a paragraph and state it in the next form:

The appeals from citizens are accepted in written form, in the form of electronic messages, as well as phone calls. The appeal should not be impersonal and should contain a surname, name, patronymic, contact phone number and the actual address of the residence of citizens. The appeals are accepted in relation to the behavior of a particular animal. The appeals containing information about the unmotivated aggressive behavior of a group of animals, in terms of the assessment of the presence of signs of unmotivated aggression in the behavior of animals, should be considered in order to find unmotivated aggression in specific animals.

The work with the appeals of citizens by a person who, in accordance with the requirements of Law No. 498-FZ and the regulatory legal acts of the constituent entity of the Russian Federation, is engaged in the treatment of stray animals is carried out within the time frame and procedure established by the Federal Law dated 02.05.2006 No. 59-FL "On the procedure for the consideration of appeals from citizens of the Russian Federation".

During the analysis of treatment, the presence of signs in animal behavior, indicating unmotivated aggression, is assessed by:

1. The transition to aggressive behavior without prior demonstration of threat or fear (barking, growling or other forms of intimidation).

2. The transition to aggressive behavior after the behavior, loyal to a person for no apparent reason.

3. Repeated change of loyal behavior to threatening and vice versa during contact.

4. Aggressive behavior associated with other forms of activity that are atypical for these animals (unusual movements, uncharacteristic behavior).

5. Aggressive behavior in response to a neutral signal (typical for a given territory, not posing a threat, a low sound, light, other external changes in the situation not related to an animal) or without it.

6. An animal expressing aggression outside a group.

7. An animal is classified as a potentially dangerous dog.
8. The manifestation by other animals of a group of aggression towards a particular animal.

Further, we supplemented the text with the following paragraph:

A person carrying out the treatment of stray animals in the relevant territory is recommended to travel to the address indicated in the appeal and check the reliability of the information contained in the appeal, observing the behavior of an animal in its habitat, with the purpose of preliminary examination for the presence (absence) of unmotivated aggressiveness of an animal. If any of 1-4 signs, or a combination of two or more 5-8 signs is confirmed, an animal is recognized as possibly expressing unmotivated aggressiveness (suspicious) and must be trapped and placed in a shelter.

A person carrying the treatment of stray animals must have a shelter for keeping animals without owners (or have an agreement with an organization that maintains stray animals) that complies with the requirements of the legislation of the Russian Federation, as well as the laws adopted in accordance with them and other regulatory legal acts of the constituent entities of the Russian Federation and regulatory legal acts of local governments.

Next, we propose to include a paragraph with the following content:

The final examination for the presence (absence) in stray animals of unmotivated aggressiveness should be carried out in an animal shelter.

Stray animals which were staying in an animal shelter for at least 3 and no more than 7 days can be examined for the presence (absence) in stray animals of unmotivated aggressiveness.

Before the beginning of the examination, a stray animal must be in the room where the examination is carried out for at least 1 hour.

Further, the next three paragraphs must be as follows:

The examination is recommended to be carried out in a room unfamiliar to a stray animal (room or cage). The size of a room or a cage must be large enough to comply with the standards for keeping stray animals, established by the regulatory legal acts of the constituent entities of the Russian Federation, so that a stray animal does not feel fear of a closed space and can move freely.

A cage or crate should have three blank walls and one wall, covered with a net.

A person carrying out activities for the treatment of stray animals in the relevant territory or an employee of a shelter authorized by him, carrying out an examination for the presence (absence) in stray animals of unmotivated aggressiveness, must be a specialist in the field of veterinary medicine with a higher veterinary education, who have undergone professional retraining in cynology or animal psychology.

If any of 1-4 signs or a combination of two or more 5-8 signs is confirmed, an animal is recognized as expressing unmotivated aggressiveness.

We consider it necessary to state the following two paragraphs in the following way:

According to the results of the inspection, a person carrying out the treatment of stray animals in the relevant territory or an employee of an animal shelter 
authorized by him or her shall fill in the appropriate act of the examination of an animal for the expression of unmotivated aggressiveness, including a photo of a tested animal. Based on the results of the inspection, a person carrying out the treatment of stray animals in the relevant territory, if an animal is recognized as possibly expressing unmotivated aggressiveness (suspicious), a decision is made to trap such an animal and place it in a shelter, in accordance with the procedure established by the law No. 498 -FL.

Next, the text should be supplemented with the following paragraph:

According to the results of the inspection, by a person working with stray animals or by an authorized employee of a shelter in the territory of an animal shelter, if an animal is recognized as expressing unmotivated aggression, a decision is made on its placement in a shelter and the possibility of its return to its former habitat.

At the end of the methodological recommendations, we propose to include Appendix 1: The act of the examination of an animal for the manifestation of unmotivated aggressiveness.

The adoption of the "Guidelines for the constituent entities of the Russian Federation to find stray animals expressing unmotivated aggressiveness" will allow regional executive authorities to develop their own "Guidelines for the constituent entities of the Russian Federation to find stray animals expressing unmotivated aggressiveness" and form a more complete regulatory and legal framework for shelters for stray animals, including the regulation of the procedure for their veterinary services.

\section{Conclusion}

The modern problem of urban and large rural settlements of the Russian Federation is the increase in the number of stray animals. The activity of shelters for stray animals is associated with a number of obligatory veterinary preventive measures, as well as the castration (sterilization) of animals. All this requires the development of a comprehensive system of veterinary services for animal shelters, including the procedure for the initial admission of an animal to a shelter, the procedure to find a stray animal expressing unmotivated aggressiveness, a system of veterinary preventive measures in a shelter, a method of humane treatment of animals in a shelter, the typical staffing of veterinary shelter specialists and a typical diet for an animal in a shelter. In many constituent entities of the Russian Federation, there are no state shelters for stray animals. The activities to regulate the number of stray animals are mainly carried out by private specialized organizations in accordance with the concluded municipal contracts, in view of the fact that most often it is the municipal authorities that are responsible to control the number of stray animals in the territories of municipalities. Other researchers studying the issues of exercising powers to treat stray animals in the constituent entities of the Russian Federation also point out to this aspect $[9,10]$.
The current practice does not allow organizing a general effective system to regulate the number of stray animals, which would accessible to the zoo-protective community and provide reliable prevention of diseases common to humans and animals, the causes of which are the populations of stray animals. A regional system for the regulation of the number of stray animals could be organized under the leadership of the State Veterinary Service of the constituent entities of the Russian Federation in cooperation with existing private shelters for stray animals. This system can not be created without an appropriate regional regulatory framework regulating the activities of these shelters, which, in our opinion, in addition to the already adopted regulatory legal acts, should include the "Procedure to find stray animals expressing unmotivated aggressiveness", as well as regulatory legal acts regulating the procedure for the initial admission of an animal to a shelter, a system of veterinary and prophylactic measures in the shelter, the method of humane treatment of animals in a shelter, a typical staffing of veterinarians at a shelter and a typical diet for an animal in a shelter.

The development and implementation of proposed comprehensive system of veterinary services for animal shelters, which can not be created without the presence of an appropriate regulatory and legal framework, will serve as one of the elements to maintain the epizootic and epidemic well-being of the territories of the constituent entities of the Russian Federation for zooanthroponosis, among which rabies is the most relevant in recent years.

\section{References}

1. A.A. Butova, M.N. Vasiliev, Scientific Notes of Kazan SAVM, 243, 44-48 (2020)

2. N. Turken, J.E. Carrillo, A. Paul, European Journal of Operational Research, 292(1), 299-310 (2021)

3. E. Ofensberger, Deutsche Tierarztliche Wochenschrift, 112(3), 107-111 (2005)

4. Ch. Wilczek, Deutsche Tierarztliche Wochenschrift, 115(3), 101-105 (2008)

5. H.M. Spasowska-Czarny, Lex Localis, 18(4), 767790 (2020)

6. M. Truszczynska, J. Szarek, M.Z. Felsmann, Medycyna Weterynaryjna, 59(4), 354-358 (2003)

7. A.P. Anisimov, Bulletin of the Saratov University. New series. Series Economics. Control. Law, 19(4), 415-421 (2019)

8. D.V. Zahodnova, M.V. Vinohodova, D.A. Pomerancev, I.I. Shershneva, D.A. Orehov, Regulatory issues in veterinary medicine, 3, 29-35 (2020)

9. K.V. Khvastunov, Municipality: Economy and Governance, 2(27), 99-104 (2019)

10. A.F. Sabiryanov, Scientific Notes of Kazan SAVM, 234, 166-169 (2018) 